\title{
Time out of mind? Picturing presence in future research
}

\author{
Friederike Müller-Friemauth • Eckard Minx
}

Received: 15 June 2014 / Accepted: 30 October 2014 / Published online: 5 December 2014

(C) The Author(s) 2014. This article is published with open access at Springerlink.com

\begin{abstract}
It is above all sociology and media theory which to an increasing extent are providing impulses for redefining the modern semantics of the concept of time. At the focus of attention here is the explication of the present and, as an indirect consequence, a chronodiagnostically founded discrimination of the concept of future. The discourse is concerned with the semantic field of simultaneity, synchronisation and above all "presentism". The background and motive of this discussion are on the one hand transformations in the modern scientific view of the world, but on the other hand new descriptions of social reality — particularly of decision-making and actions under conditions of complexity and thus of uncertainty.

The article deals with the question of whether this discourse, which is taking place on a number of conceptual levels predominantly within the German-speaking world, affects the interests of future research, and if so, how. The authors base their investigation on practical questions developed from the point of view of organisations: What does this discussion mean for the future plans of institutions and political and economic organisations? The article begins by offering a scientific classification of the debate, before underlining its most important defining concepts. Finally, the authors outline the initial methodological consequences for future-oriented action within organisations that would be appropriate considering the complex, dynamic conditions currently prevalent in our economy and society.
\end{abstract}

F. Müller-Friemauth $(\bowtie)$

FOM Rheinauhafen Süd, Agrippinawerft 4, 50678 Köln, Germany

e-mail: friederike.mueller-friemauth@fom.de

E. Minx

Stubenrauchstr. 2, D-12161 Berlin, Germany

e-mail: estmx@gmx.de
Keywords Future research · Time binding $\cdot$ Presentism • Mobility $\cdot$ Scenario $\cdot$ Forecast $\cdot$ Prognosis $\cdot$ Early warning

The recently published best-seller by U.S. media theorist Douglas Rushkoff succinctly expresses what many-mostly sociologically oriented and intensively in the germanspeaking world located - observers have already been stating for many years: compared with the present, the future has fallen far behind in terms of zeitgeist. Rushkoff refers to this as "presentism". Under this label, he groups together a semantic field centred on simultaneity, links, networking and synchronisation. "If the end of the twentieth century can be characterized by futurism, the twenty-first can be by presentism" [1]. In the interest of future research, the question may be asked: if this is not a passing fad, what is? And: is it of disciplinary importance?

This discourse is taking place among the scientific disciplines that have invariably projected into fields of interest covered by future research: sociology, political science, philosophy of technology, or education research, for example. This refers to activities that are not positioned outside the main interest fields of Foresight (such as demographic research, climate research or technological impact assessment), but which are aimed directly at its core. In the field of social sciences, these are on the one hand contributions to the development of modern semantics of time [2-9], and on the other hand chronodiagnostic studies of changes in our perception of progress, of shifts in the zeitgeist or of acceleration phenomenologies $[1,10-15]{ }^{1}$ This branch of discourse is not new either, nor is it exclusively future-oriented - but it is relevant to

\footnotetext{
${ }^{1}$ In the first group, aspects are broached that are further discussed in the following under a specifically future research-oriented perspective: viz. a displacement in the concepts of time with regard to order. The second group mentioned here is characterised by a more strongly phenomenological and chronodiagnostic argumentation.
} 
future research: if future research is concerned with the temporal dimension of the future and is required to provide epistemological and methodological substantiation to its statements in reference to the future, up-to-date concepts of the quality of time are highly relevant.

In the narrower context of future research, such activitiesi.e. observations of transformational trends within the core field of the discipline - are not adopted, as far as we are aware. $^{2}$ It appears to us worthwhile and imperative to remedy this state of affairs. In doing so, our perspective is related to organisations, which efforts in foresight activities ("detecting the future", i.e. by means of monitoring and scanning) with increasing frequency hit the wall. Results are going to be contingent and require explanations (why detecting this weak signal and not that?). In addition to it the quantity of signals explode. The rising complexity of the settings in which organisations act and decide face them with so far unsolved methodological challenges. We ask if the debate about presentism is able to help putting this dramatised perception of the issue into proper proportion; possibly illustrating not a short cut, but something along the lines of a clarifying, inspiring perspective at least.

Whether this above all sociologically conducted parallel discourse concerning the transformation of the current concept of time can be rendered fruitful to the interests of future research - and if so, how - is the subject of this paper. At the outset, we give a cursory presentation of central positions of this new version of an up-to-date understanding of the future and summarise the requirements that can thereby be deduced for dealing with the future (I). Subsequently we expose the specific features, which are central (II). Finally, we discuss possible consequences for a future research in organisations that methodically places the condition and the transformation of its very own object area - a constantly updated concept of the semantics of time - at the centre of its attention (III).

\section{Evolution of the understanding of time}

Time is invariably also a concept of politics in theory - there is timing in everything. Its understanding is subject to the "zeitgeist" - or more precisely, to the mutable social construction of reality. Indicators of a transformation are currently claimed by two sides: on the one hand by the natural sciences, particularly in view of advances in the physical concept of the world. In his semantic analysis of the concept of time the sociologist Niklas Luhmann, for example, explicitly refers to advances in knowledge that were only made possible by

\footnotetext{
2 The concept and understanding of the future constitute a topic in itself (instructive for example [16]), however not with a chronodiagnostic, but with a historical or definitional-conceptual intention.
}

Einstein's Theory of Relativity. ${ }^{3}$ On the other hand, the topic is also treated under the aspect of subject philosophy, which focuses on descriptions of both subjective and individualpsychologically coloured sensation, which goes hand in hand with a new understanding of time. These phenomenologies of lament are centred around temporal stress, hectic activity over a prolonged period, haste or tiredness, excessive demands due to acceleration processes, overburden and increasingly prevalent pathological conditions such as depression and burnout, the cause of which is at least in part attributed to a change in quality of time that is yet to be mastered. With a view to our methodical interest, in the following we shall concentrate on the first strand.

\section{What is "presentism"?}

A rough concept of time that is adequate to the current state of knowledge draws on advances above all in natural scientific disciplines. Just as location and time in theoretical physics have no longer been able to be regarded as mutually independent since the 20th century, time in a social context can now no longer adequately be derived from the phenomenon of motion: the traditional-modern dichotomy "before-after" was bound to a fixed space within which the procession of time can be observed (earlier-later). The premise of simultaneity is the new point of departure for the observation of time: everything that occurs, occurs simultaneously. ${ }^{4}$

This at first appears banal in phenomenological terms: it is obvious that something new can occur neither in the past nor in the future, but only at the present moment - but then simultaneously. In any case, something can only happen "now". This premise only gains analytical acuity in the age of complexity with a signature of the zeitgeist, which has already long contended with numerous problems pertaining to reproduction and - as a result - with selection of a social, technological, political or other nature due to individualisation, pluralisation, globalisation, technologisation and the formation of networks; in other words with various functional and other systemic differentiations.

However, when a great deal (perceived as: an ever greater quantity) of changes occur in parallel and within a short time (perceived as: increasingly rapidly and frequently), the "rupture" between past and future becomes more radical: with increasing probability, the future no longer resembles the

\footnotetext{
${ }^{3}$ See [8], p. 99 FN 12.

${ }^{4}$ See [8] p. 98. Along with the Theory of Relativity, Heisenberg's Uncertainty Principle could be cited as a further parallel from natural science, according to which a particle can be detected at two different locations at the same time. According to quantum mechanics, this is due to the wave character of matter. - Independently of the respective specific anchor points, the authors under discussion here endeavour to make advances in knowledge from the modern natural sciences accessible to the social sciences.
} 
present or the past. How it eventuates is determined by what is selected as being significant today and is further pursued - in other words by how decisions are made. Time thus "shrinks" to the dimension of the present; it "contracts". 5 This situation gives rise to several consequences, including a fundamental dilemma: since a variety of problematic situations arose from the dynamics of past developments that proved basically insoluble (such as the German "energy turnaround"), the pressure of decision-making swells like an immense wave and increasingly reinforces the necessity of future-proof solutions.

It is such implications of an "extended present" that fuel the debate concerning "presentism".

What does this mean for future research?

Attention is initially drawn to everything that increases the quality of decisions currently under discussion. In an "extended present", future research is increasingly transformed into an evaluation technique: the future is essentially dependent on the way in which something new is identified and ordered. It is concerned both with discarding irrelevant terms from the complex of simultaneity and with selecting something that is specific, important, complex, insecure, is not yet in existence or only appears diffuse. This intelligent modularisation of possibilities is becoming the core competence of future research. In any case, the focus is no longer on the intrinsic value of what is new, of what is yet to be: the future.

Is future research thus possibly losing its grip on its entire field of investigation? No - but it is undergoing significant transformation. In the light of entrepreneurial focus, this means for example: future research is becoming more and more an auxiliary discipline for entrepreneurial decision-making. Under conditions of high complexity, it combines existing know-how and knowledge with future hypotheses - in the mode of the present: if what lies in front of us no longer offers criteria for selection because it has become so extensive, confusing, insecure and even uncertain, all that remains for us is to contemplate selection criteria more intensively that are anchored in the here and now. The aim is to regain security, but differently from in the past.

Contemporary future research thus unifies the two aspects: it ascribes the assets of an enterprise to notoriously insecure, invariably controversial trend hypotheses. Future research is thereby becoming more present-oriented ${ }^{6}$ : this means presentism for future research. Modern future research reduces the

\footnotetext{
${ }^{5}$ See [8], p. 117 - a formulation by Nikolaus von Kues.

${ }^{6}$ Which does not mean that future research must or should adopt the analysis of shorter time horizons. By "orientation towards the present", more of an alignment is intended here: between assumed future developments (anticipation, hypotheses) and parameters of those protagonists who analyse the future (an experience- and context-bound, individual and therefore changing decision-making perspective).
}

focus on the future and increases the focus on the present. Its metier is the synchronisation of already existing, promising points of departure or springboards, in an organisation for example, with "good" hypotheses for promising eventualities: alone in view of rapidly increasing complexity, the future no longer yields a valid basis for decision-making. ${ }^{7}$

\section{Peculiarities of presentism}

In schematical terms, the consequence of the discourse of presentism means: Not looking forwards and detecting tomorrow but exploring occurences of the presence. In methodical terms, future research projects notional causalities into the domain of combinatorial possibilities that management can then utilise to arrive at a decision. It systematically develops broad assumptions: if you do $\mathrm{x}, \mathrm{y}$ can result; if you prevent $\mathrm{z}$, you will have the chance of $\mathrm{m}$. In this process, it endeavours to impose methodical checks on its cause-and-effect hypotheses.

For practitioner in organisations - especially decision makers - this new focus on intellectual, imaginary forms of control and securing is interesting: Traditional kinds of control come under fire for some time in particular the more organisations are arranged in a modern manner, with advanced views (participative management style, flat hierarchies, selforganized units and so forth). In this context the perspective of presentism is fascinating because of its potential style-forming thought patterns: It might be that this is the core of an up-todate provisional thinking based on future research which modifies the understanding of security and control, at times fundamentally - and in many ways:

1. Primacy of simultaneity. Future research must order and put things into relation in terms of time - "temporalise". One can neither know beforehand what events will occur simultaneously, nor it is clear in which relation they will then stand to the past (follow-up) or to the future (precaution). The principal task of future research is therefore experimental formation: on the one hand, times are treated in a playful manner; they are placed in relation to one another. When is a specific technological breakthrough to be expected; where do one's own resources stand in relation to this; what intervening variables must definitely be taken into account? On the other hand, that which is not yet current in temporal terms must be transported into the objective and social dimensions and examined there:

\footnotetext{
${ }^{7}$ This has always been the case - the "business model" of the Oracle of Delphi is an excellent basis for studying how the ancient Greeks, for example, negotiated this problem. However, this insight has long since departed from the temples of the priests and gurus. For decisions under conditions of high uncertainty in the early 21 st century, this is now common practice. This is new, and not the fact in itself.
} 
what are the opportunities, the risks, the dangers? Luhmann speaks in this connection of "synchronisation" or "time binding". This is concerned with mind games, with provisional thinking, which sets out to render time in convenient forms. ${ }^{8}$

Behind this concept are fundamental assumptions relating to future research that cannot be discussed here in detail. Basically, we are dealing here with the generation of alternative future-related bottleneck strategies between the three poles of consensus, object and time. The dimension of time is consistently privileged here over the objective and social dimensions. Exactly this is not only the focus of presentims, but also the assignment of future research. Chance-risk analyses, for example, are already being worked on by the economic sciences, and problems of decision-making or arriving at a consensus by sociology and social psychology, and so on. Future research supports decisions made under conditions of high uncertainty - from the viewpoint of presentism - by temporalising the conditions for decision-making: this is "time binding". In organisations, for example, it installs appropriate time regimes that structure, but also impose limits on, systems of values. What differentiates it from other influences on decisions made in conditions of uncertainty, for example on the part of the economic sciences, is the concentrated modularisation of temporality: what will happen when; what could happen when; what is not likely to happen? This methodical, "temporalising" reflection loop is a safeguarding mode - in a decidedly temporal dimension. It endeavours to control self-created (imagined) options in contrast to that which is known for certain [17]; only then do other disciplinary expertises follow.

2. Primacy of projection. When it comes to looking forward, future research is finding it increasingly difficult to rely on prognoses alone; after all, however precise the data may be that serve as a basis for the respective calculations, forecasts fundamentally claim to be able to make a reliable statement as to which events will win out in future [18] - in other words, which development path will ultimately prevail in the evolutionary process. If future research takes seriously the conditions of modern complexity, however, it cannot even state which events will occur simultaneously, let alone which of them will ultimately prevail. But what it can do is to test alternative corridors -

\footnotetext{
8 "Synchronisation binds the medium of time to forms (time binding) and sets out in search of favourable forms. But there is no supersynchronisation that could regulate synchronisation itself. This was formerly referred to as fate." [8], p. 118. Nevertheless, there exist rules for arriving at a verdict or a decision that help render synchronisation differentiable as better or more adequate (to the situation or the subject), or to a lesser extent or less adequate. Identifying such meta-rules is one of the tasks of future research and a key task of provisional thinking.
}

to project different variants of what manifests itself today as weak signals with a view to possible successes. The focus is shifting from prognosis to projection. Systematic thinking in alternatives is also a control mechanism.

3. Reduction of complexity instead of monitoring of something always new. The hypotheses that it sees as relevant must be reduced to a normal measure that is still tolerable in borderline cases. It must offer operations for "reducing" what is possible: selection mechanisms, filter methods, exclusion techniques. These are strongly dependent on context and often still remain to be developed in individual cases.

Along with monitoring techniques for the recognition of new elements, a new branch of methodology is arising: the art of reduction, omission, judicious avoidance. This does not refer to banal simplification, but indeed to the exclusion principle: the mandatory requirement for reduced complexity. This too serves as a safeguarding mechanism.

4. Full responsibility of the decision maker. Future research must declare binding a decision corridor that appears relevant, even if the decision is to be binding. Whereas in the past, one could pass on the "responsibility" for future-related decisions to the trend or to the predicted phenomenon - in other words pass it off: "that will come!" - such exoneration is no longer valid today: in the immense event forest of modern complexity, the individual trees are now barely discernible. This is uncomfortable for future research, but makes much clearer what it is in fact capable of: not looking into a crystal ball or taking a stab in the dark of the future, but decision management [19]. With results at one's own risk: the selection of the appropriate decision corridor can only be made against the background of one's own abilities and options. This modifies the concept of decision-making; it is "automatically" extended by an ethical component (responsibility). ${ }^{9}$

5. New Methods - i.e. synchronisation. Future research must regulate the pace at which new hypotheses are utilised. One can also do too much, arrive too early or too late, innovate too often or not often enough, for example. This is normally dependent on the line of business and the individual case and can assume highly diverse forms.

Here too, time binding is in the foreground - regulators

\footnotetext{
${ }^{9}$ In this connection, we do not mean moral responsibility with a view to one's surroundings and society (for example in terms of ecological issues) extending "to the outside", but rather a modern form of responsibility that lies exclusively with the decision-maker and only relates to him: what eventuates (fate, prophecy, prognosis, "stable" trends etc.) is no longer the "fault" of the future; it is exclusively the "fault" of the decision-maker, who makes this decision and no other. Here too, we are merely drawing the conclusion from the transformation of our zeitgeist-oriented selfunderstanding: what has changed is our apperception, not the circumstances themselves.
} 
that precisely position a decision in terms of time. One methodical possibility of doing this is to think more intensively than usual in variable temporal structures, using scenario techniques: playing at different innovational tempi in the organisations (not with supposedly weak or strong dynamics of trends!), with one's own formative levers in the sense of "accelerators" or "retarders" (not "drivers" or "preventers"!) and so on. Here too, it is necessary to consistently privilege the dimension of time.

This list is incomplete - it is more of an initial outline than an exhaustive register. A rough profile of this modernised future research is nevertheless already discernible.

\section{Future research: a profession for "time binding"}

The debate surrounding presentism brings up methodological idiosyncrasies associated with future research that have gone previously unnoticed. The significance of these idiosyncrasies to future research moving forward must be discussed and assessed. Investigating the future

- by assessing simultaneously occurring events against and comparing them with one another instead of looking to tomorrow;

- which, due to the fundamental unpredictability of the future, limits us to "simple" projection, as opposed to actual forecasting;

- in such a way that circumstantial information is, due to its excessive complexity, predominantly subject to radical filtering, yet can also be enriched by further monitoring in exceptional cases;

- using patterns of legitimation whereby future-related decisions are no longer justified by events (past, present or future), but instead solely by the will of the decisionmakers;

- by training a series of new skills and methods relating predominantly to a comparative assessment of events occurring simultaneously in the present that can thus no longer be analysed causally (prior cause - subsequent effect). This will, in turn, change the central analytical perspective from causality to synchronisation;

this approach is not only unusual, it is also counter-intuitive for future research. This seems to be causing future research to collapse or implode into a profession that, although specialised - as indeed all sciences are - focuses solely on observing the present. Will the future research eventually be condemned, like the owls of Minerva, to fly only by night? Are we dealing with a form of "catch-up modernisation" that will end up deflating future research as a discipline?
If one aims to use the debate surrounding presentism constructively, it is possible to compile at least a few requirements for this distinctive approach to future research. We shall do this using seven theses and experimentally expand on the ideas from certain aspects of the points raised in this debate.

Future research has a conceptual deficit. Its central categories are under-determined

We must begin by clarifying how the core canon of central future research concepts itself should look. Indisputably, the concept of time must be clarified; in a way that is both contemporary and somewhat in keeping with current scientific theory. The fact that almost all modern approaches to, schools of and perspectives on future research still remain rooted in the foundations of early modern physics as established by Newton, Copernicus and Galileo (a linear timeline from the past, through the present, to the future), is not an endorsement of quality for a discipline that aims to build expertise for leaps in time.

Future research 1.0 was based on this very premise: that phenomena develop in time. Attention was thus focussed on the "discovery" of rules, laws and principles governing such developments. For a number of decades, trend research for example functioned just like this: trend signals in the sense of deviations from the "norm" were identifiable as relevant on the one hand and as unambiguous on the other and could thus be analysed with a view to their causes, emergence and dynamics. This was the age of "trend-building". In our age of simultaneity, however, we are drowning in the sea of events. Everything is first of all equally relevant - and who would dare to say what event is more relevant or the most relevant? This mood - which essentially bewails the interchangeability of models of reality, their rapid change and their eventual unsubstantiable nature - is exactly what is reflected by presentism.

The thesis that a re-conceptualisation of time can offer us new structural perspectives is instructive. The beginning of the 20th Century heralded a caesura in natural sciences, and especially in physics, that is almost entirely unreflected in future research. As stated above, we are calling this into question purely for practical reasons. Adopting a concept of time based on simultaneity and uncertainty theories (Planck, Bohr, Einstein, Heisenberg et al.) as proposed in Luhmann's evolution theory perspective on organisations, may be highly abstract in theory, but it has heavy practical repercussions. The fact that the consequences of this shift, which is now almost one hundred years old, have not yet been fathomed makes it all the more urgent that we do so now. From our point of view, the "catch-up modernism" that could refer here to presentism is thus not an implosion of the profession, but a momentous turning point - befitting a discipline that tends toward sudden leaps in conceptional consolidation. 
Presentism illuminates a fundamental question relating to future research that has, until now, remained largely unanswered: what is it responsible for?

For not being misread: This question we do not mean objectively, "topically". From a practical - more precise: praxeological - point of view, future research can be seen as being founded on 1 of at least 2 perspectives. Future research may be responsible for all conceivable factual and social (social, economic, political, technological etc.) problems but only with a view to tomorrow. How will the ecological situation develop? What customer groups will form in India? What does 3D printing mean for private households? From this perspective, future researcher are no more than consultants - corporate advisors, technology managers, innovation experts or social researchers with an eye for the new, for emerging trends and for unusual evolutionary paths. Topical experts with a penchant for scouting.

Alternatively, future research may be genuinely founded on its field of expertise and the analytical dimension of time consistently prioritised. This would make the field a form of expertise for leap in time of a completely different type; for questions such as: How can we use past experience (directly or in a revised form)? How can we shape current events to work in our favour? How can we help to make a specific development path that is more or less preferable to us more or less probable? What type of innovation would be required in order to make a specific circumstance $\mathrm{x}$ at all logically plausible in y years?

So far, the core source of expertise for these types of questions has been therapists and psychologists, or mystics, clairvoyants and gurus. This tradition was founded by the ancient Oracle of Delphi, traces of whose prophecies can still be seen in modern future research. Is it possible to use another: modern and scientific basis to alter future circumstances (working and rehearsing on a conceptual level) that can be connected to our current level of knowledge, comply with modern standards of legitimacy and justification (whether educational, normative, scientific, with criteria such as verifiability, validity etc.) and still yield results that offer a valuable contribution and make a difference when compared with other disciplines? The starting point for this type of future research would be a discipline that specialises in the reflexive generation of time-strategic "immersions" based on the conditions of their fundamental nonlegitimacy (contingency). It would be a specialist in developing credentials for time strategies that could look different every time, yet would or could be given priority in this specific situation for definable reasons. Concepts for the foundation of such a perspective have existed for some time, but they have yet to truly take hold in the world of future research $[20,21]$.
Presentism calls into question the relevance of established methods of future research (scenario development, forecasting, backcasting, prediction, projection, what-if-frames etc.) to the modern day. The discourse thus takes sides, praising (i.e. synchronisation) and discriminating (i.e.prediction). It thus criticises methodological indiscrimination and demands criteria for judgements and assessments

Presentism suggests that some methods are more modern and legitimate today than others. Based on a modern concept of time, synchronisation, which is always committed and necessarily tied to a "decisionistic" form of evaluation, is better equipped to present simultaneous events than the results-oriented, pseudo-precise prognostic approach to future events, which is based on unfounded knowledge. There is not only a lack of precise, considered standards of evaluation between such approaches. The question of how the "synchronisation"method actually works also remains largely unanswered. The debate surrounding presentism provides a host of creative boosts for refreshing the portfolio of methods.

Presentism severely questions the fixation on that which is new ("newism")

According to the pleas of presentism, future research should concentrate on working with a selected (how?), few (why these, specifically?), relevant (how is this determined?) levers, signals or future-related aspects of the present, and use this minimised, relevant set to alter interdependencies and side effects of alternative future paths. This is - at long last - a clearly delineated proposal to tackle complexity. To what this will lead has to be discussed and checked. It is certainly nothing new: followers of Frederic Vester in the St Gallen school in the 1980s and 1990s researched precisely this type of process, albeit in relation to physiological brain processes related to human learning. The debate surrounding presentism could herald a revival of this perspective - motivated by the diagnosis of time with a disciplinary use.

Presentism pokes once at the wound of classical decision theory, albeit from a different angle. Many voices in economic sciences have been doing this for decades; the most prominent branch of discourse is probably the criticism of homo oeconomicus. The behavioural economics, profit-calculating focus of decision theory used in business studies and probability theory and criticised here is out of line with presentism from a specific perspective: for future-related decisions - i.e. decisions made with radical uncertainty in complex situations - it is useless

This leads to a number of interesting questions for organisations whose practical development and requirements are based 
on effective provision for the future: What standards exist for "good" future-related decisions? What does "good" even mean in this context? How is it qualified? What makes this type of decision special: What "can it do" particularly well, or at least better than others? According to presentism, the only available answers are: "Good" does not mean reclaiming a leap in knowledge for tomorrow (this is logically impossible), be this for reasons of authority (guru positioning), methodology (having the best algorithm, monitoring system etc.) or technology (being first to market, "newism", the next big thing etc.). "Good" also cannot mean: safe, optimal, best-case. It can only ever be a preferred suggestion under these precise, specific, situational conditions. Furthermore, this type of decision is "special" not because of its hip, modern methods or the cool image of its protagonists, but because of its specific position in relation to a reality that is constantly and unavoidably changing in modern times. This last point is the most delicate - it affects key fundamental aspects of the way we understand (organisational) practice.

Presentism highlights how important the present is for future research

This is also not a new concept in the field of future research. Nevertheless, it would be counter-intuitive to make it the centre of future research: presentism attempts paradoxically to "lock" the future. It implores us to think not of "all that is possible", but primarily of that which can be influenced. (This is why all monitoring of the environment tends to be seen as futile in this way of thinking). The path is being systematically diverted towards a varied "multi-optionism"- or that is the claim, at least. For practitioners of future provision, this is an extremely interesting message: it seems to illuminate a path upon which excessive circumstantial complexity could be solved "internally". Explaining how this works is one of the core tasks of future research.

Many commentators have already long been pointing out the "upswing" of the present - this could therefore have known earlier. Rushkoff only elucidates this situation for a broad audience. Future research must take care that it is not surprised, overtaken or even left behind by some parallel discourse or other. The conceited hermeticism of this sector is no longer appropriate to a complex, networked world

To cite an example: future research is not a "makeshift science" 10 simply because it is still devoid of high ivory towers (which nobody needs), but among other things because its protagonists neglect to seek out points of contact to neighbouring disciplines. The equivalent of open innovation in the economic sciences would be for example: receiving

$\overline{{ }^{10} \mathrm{Cf} . \text { [22], [23] }}$ transdisciplinary parallel discourses, also taking the practitioners seriously for a change (from the "outcome-oriented", possibly less prestigious small-business operator up to the consultant) and not allowing the homespun debate about deficient "academisation" to become a pseudo-professional visual cover. Anticipatory consideration of possible developments within one's own discipline is likewise a task of selfinformed future research (self-reflectivity). It is not an unshakable natural principle that transformations in the foundation are necessarily a shock - the Future Shock of Tofler from 1970, or now the Presence Shock of Rushkoff. It is conspicuous that the seismographic competence of the Americans regarding such transformations is not invariably more finely tuned than that of the Europeans; the current shift was arranged and partly initialized at an early stage in Germanspeaking countries.

"The intellectual resources of thinking about the future today offer few perspectives," stated Luhmann as recently as 1991 [24].

We have the impression that this is currently changing.

Open Access This article is distributed under the terms of the Creative Commons Attribution License which permits any use, distribution, and reproduction in any medium, provided the original author(s) and the source are credited.

\section{References}

1. Rushkoff D (2013) Present Shock. When Everything Happens Now. New York, p. 3

2. Assmann A (2013) Ist die Zeit aus den Fugen? Aufstieg und Fall des Zeitregimes der Moderne. München

3. Esposito E (2007) Die Fiktion der wahrscheinlichen Realität. Frankfurt a.M

4. Esposito E (2010) Die Zukunft der Futures: Die Zeit des Geldes in Finanzwelt und Gesellschaft. Heidelberg

5. Geyer C (2013) Niklas Luhmann. Die Knappheit der Zeit und die Vordringlichkeit des Befristeten. Berlin

6. Koselleck R (1979) Vergangene Zukunft. Zur Semantik geschichtlicher Zeiten. Frankfurt/M

7. Lübbe H (2003) Im Zug der Zeit. Verkürzter Aufenthalt in der Gegenwart. Berlin/Heidelberg

8. Luhmann N (1990) Soziologische Aufklärung 5. Konstruktivistische Perspektiven. Opladen

9. Nassehi A (2008) Die Zeit der Gesellschaft. Auf dem Weg zu einer soziologischen Theorie der Zeit. Neuauflage mit einem Beitrag "Gegenwarten". Wiesbaden

10. Gumbrecht HU (2010) Unsere breite Gegenwart. Berlin 2010

11. Gumbrecht HU (2012) Präsenz. Berlin

12. Han B-C (2010) Müdigkeitsgesellschaft. Berlin

13. Nowottny H (1989) Eigenzeit. Entstehung und Strukturierung eines Zeitgefühls. Frankfurt a.M

14. Rosa H (2005) Beschleunigung. Die Veränderung der Zeitstrukturen in der. Moderne. Frankfurt

15. Rosa H (2013) Beschleunigung und Entfremdung: Entwurf einer kritischen Theorie moderner Zeitlichkeit. Frankfurt 
16. Grunwald A (2009) Wovon ist die Zukunftsforschung eine Wissenschaft. In: Popp R / Schall E (Ed.) (2009) Zukunftsforschung und Zukunftsgestaltung. Beiträge aus Wissenschaft und Praxis. Berlin/ Heidelberg, pp. 25-35

17. Ingvar D (1985) Memory of the future: an essay on the temporal organization of conscious awareness. Hum Neurobiol 4(3):127-136

18. Neuhaus C / Minx E (2009) Die Zukunft ist anders anders. Extrapolation und Konstanzannahmen als Instrumente und Fallstricke der Zukunftsschau. In: Reimer, Marko / Fiege, Stefanie (eds.) 2009. Perspektiven des Strategischen Controlling. Festschrift für Prof. Dr. Ulrich Krystek, Wiesbaden, pp. 229-238

19. Müller-Friemauth F (2013) No Such Future. Ein Trainingslager für mittelständischen Unternehmerverstand. Offenbach, pp. 159-165
20. Rorty R (1995) Philosophy \& The Future, in: Herman J. Saatkamp (Ed.) Rorty \& Pragmatism: The Philosopher Responds to His Critics, Vanderbilt University Press

21. Stachowiak H (Ed.) 1986-1995: Pragmatik: Handbuch pragmatischen Denkens (ed.), 5 volumes, Hamburg 1997

22. Axel Z (2012) Gedanken zur Zukunft der Zukunftsforschung. Popp 2012:59-80

23. Popp R (Ed) 2012 Zukunft und Wissenschaft. Wege und Irrwege der Zukunftsforschung. Berlin

24. Luhmann N (1991) Risiko auf alle Fälle. Schwierigkeiten bei der Beschreibung der Zukunft. In: id.: Short Cuts, P. Gente / H. Paris / M. Weinmann (eds), Frankfurt a.M. 2000, pp. $91-98$, see 91 